\title{
Toward $\beta$-Amino Acid Proteins: Design, Synthesis, and Characterization of a Fifteen Kilodalton $\beta$-Peptide Tetramer
}

\author{
E. James Petersson ${ }^{\dagger}$ and Alanna Schepartz ${ }^{\dagger}, \ddagger$, \\ $\dagger$ Department of Chemistry, Yale University, New Haven, Connecticut 06520-8107 USA \\ $\$$ Department of Molecular, Cellular and Developmental Biology, Yale University, New Haven, Connecticut \\ 06520-8107 USA.
}

Natural proteins are composed of linear chains of $\alpha$-amino acid monomers that adopt complex folded structures stabilized by non-covalent interactions. ${ }^{1}$ Within a single polypeptide chain, local interactions generate helix or sheet secondary structures and longer-range interactions generate tertiary structures - assemblies of multiple secondary structures. ${ }^{2}$ Furthermore, multiple discrete polypeptides can associate to form quaternary complexes. This higher order structure is nearly universally responsible for the sophistication of protein function. Nonnatural polymers have the potential for structural complexity and sophisticated function, but the design of such molecules is even more challenging than protein design, because there exist no natural templates to mimic. ${ }^{3,4}$

Our efforts to design higher order $\beta$-peptide folds began with the synthesis of the oppositely charged $\beta$-peptides Acid- $1 \mathrm{~F}$ and Base- $1 \mathrm{~F}$, which assemble in aqueous buffer into a stable, octameric quaternary complex. ${ }^{5}$ To more fully characterize the structure and thermodynamics of Acid-1F/Base-1F association, we designed the dodecapeptide Zwit-1F, which we crystallized to obtain the first high-resolution images of a 14-helical $\beta$-peptide bundle. ${ }^{6} \mathrm{~A}$ detailed thermodynamic analysis established that the solution-phase behavior of Zwit- $1 \mathrm{~F}$ was consistent with an equilibrium between unfolded monomers and folded octamers with an association/folding constant of $4 \times 10^{30} \mathrm{M}^{-7}$ at $25^{\circ} \mathrm{C} .{ }^{7}$

The Zwit-1F octamer contains four copies of a parallel $\beta$-peptide dimer. Each parallel dimer associates in an anti-parallel fashion with another dimer to form a tetramer, and two tetramers assemble with a $39^{\circ}$ crossing angle to form the octamer (Figure 1A). The octamer core is composed entirely of solvent-inaccessible $\beta^{3}$-homoleucine $\left(\beta^{3} \mathrm{~L}\right)$ residues; hydrophobic burial of their sidechains presumably drives association. The solvent-exposed octamer surface is decorated by $\beta^{3} \mathrm{E}, \beta^{3} \mathrm{D}$ and $\beta^{3} \mathrm{O}$ residues that are charge-paired within the dimer unit and across the dimer/dimer or tetramer/tetramer interfaces.

While we regarded the crystal structure as an important step toward the design of a higher order $\beta$-peptide fold, several factors make Zwit-1F non-ideal. Firstly, it has a low self-affinity: the concentrations at which $50 \%\left(\mathrm{C}_{50}\right)$ or $90 \%\left(\mathrm{C}_{90}\right)$ of Zwit-1F exists in the folded, octameric state are 50 and $350 \mu \mathrm{M}$, respectively. Secondly, because of the complete surface charge pairing and exclusively 14-helical structure, the Zwit-1F octamer contains no easily modified residues and no pocket to support ligand binding and catalysis. Lastly, the octameric stoichiometry

Email: alanna.schepartz@yale.edu.

SUPPORTING INFORMATION AVAILABLE. Descriptions of the synthesis of Z28 and its characterization by MS/MS sequencing, AU, CD, ANS fluorescence, ${ }^{1} \mathrm{H}$ NMR, and SEC-LS, as well as analysis of the sidechain display angles of Zwit-1F and GCN4 are provided in Supporting Information. This material is available free of charge via the Internet at http://pubs.acs.org. 
complicates interpretation of self-association data and increases the chance that substitution of any single side chain will alter the Zwit-1F fold.

We considered two strategies to identify longer $\beta$-peptides that could recapitulate the Zwit-1F fold with fewer subunits (Figure 1A). One, which was not pursued, involves joining the antiparallel strands of a single tetramer with an appropriate (albeit lengthy) linker (Strategy A); the strategy reported here reverses the relative orientation of the two internal $\beta$-peptide monomers, converting four copies of a noncovalent parallel dimer into four copies of a covalent antiparallel dimer, Z28 (Strategy B).

To reverse the relative orientation of the two internal $\beta$-peptides in each tetramer of Zwit- $1 \mathrm{~F}$, we used Spartan ${ }^{8}$ to convert each of the four parallel $\beta$-peptide dimers that comprise the octamer into an anti-parallel dimer (Figure 1B). The side chains of the interior helix of each parallel dimer (helix 1) were disconnected and the $\beta$-peptide backbone was flipped axially by $180^{\circ}$. The side chains were then reconnected and the backbone structure energy-minimized with the sidechains fixed. The now anti-parallel $\beta$-peptide dimers were then connected by $\beta G$ linkers of varying lengths, and a four $\beta G$ linker was determined to be the shortest that could span the two helices. Finally, the resulting 28-residue structure was energy-minimized. This modeling exercise suggested that the anti-parallel helix-loop-helix structure - which we call Z28 (Figure 1C) - could replace each parallel dimer unit in Zwit-1F, effectively placing the sidechains in the same regions of space as the parallel dimer from Zwit-1F (Figure S1 in Supporting Information).

It has previously been shown that the purity of $\beta$-peptides prepared using solid-phase synthesis falls off precipitously with chain length. ${ }^{9}, 10$ We sought methods that could yield $\beta$-peptide 28 -mers of high-purity without need for large excesses of costly $\beta$-amino acid monomers. Z28 was first synthesized in the standard way, using a single coupling with three equivalents of Fmoc-protected $\beta$-amino acid monomer, HOBt, and PyBOP. Solutions of $20 \%$ piperdine (Pip) in DMF were used for Fmoc removal and both coupling and deprotection steps were performed with microwave irradiation. Most short (7- to $12 \mathrm{mer}) \beta$-peptides synthesized this way are purified effectively by a single HPLC pass in yields of 20 to $40 \%{ }^{11}$ This protocol failed for Z28: the desired product was contaminated by many peptidic side-products $(6 \%$ purity by LC area percentage, LCAP) so that we isolated Z28 in less than a $1 \%$ yield.

The synthesis and purity of Z28 were optimized in several steps. Significant improvements were observed upon inclusion of a second piperidine deprotection step and substitution of PyBOP and HOBt with PyAOP and HOAt (see Supporting Information). ${ }^{12}$ Our final synthetic procedure used three equivalents of $\beta$-amino acid, PyAOP, and HOAt; deprotections with one $20 \%$ piperidine treatment and two treatments with $2 \% \mathrm{DBU}$; and $\mathrm{Ac}_{2} \mathrm{O}$ capping after every fourth amino acid. This procedure provided Z28 in 19\% isolated yield at an LCAP purity of $42 \%$, values that compare favourably with those generally seen for $\beta$-peptide 12 mers. Thus, we avoided having to use segment condensation reactions by optimizing microwave coupling conditions for the linear synthesis of Z28.

With sufficient quantities of Z28 in hand, we characterized its association and stability using analytical ultracentrifugation (AU), circular dichroism (CD) spectroscopy, 8-analinonaphthalene sulfonate (ANS) binding and ${ }^{1} \mathrm{H}$ NMR. Consistent with our design, Z28 sedimented as an ideal tetramer upon ultracentrifugation, producing linear $\ln$

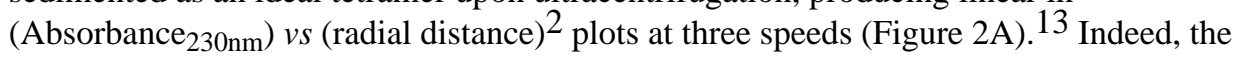
observation that $\mathrm{Z} 28$ behaves as a single ideal species implies that it possesses higher selfaffinity than Zwit-1F, which could be fit only as an equilibrating species. Moreover, the Z28 assembly is stable under a range of solution conditions - it sediments as a tetramer in Tris buffer at $\mathrm{pH} 8.5$ or 10.0 and in phosphate buffer at $\mathrm{pH} 6.0$ or 7.2. At $\mathrm{pH} 6.0$, weak dimerization 
to form octamers occurs $\left(\mathrm{C}_{50}=41 \mu \mathrm{M}, \mathrm{C}_{90}=1.9 \mathrm{mM}\right)$, but no disintegration of the tetramer is observed.

Next, we used CD spectroscopy at concentrations from 0.39 to $200 \mu \mathrm{M}$ to evaluate the stability of the tetrameric Z28 fold (Figure 2B). The molar residue ellipticity at $205 \mathrm{~nm}\left(\mathrm{MRE}_{205}\right)$ of $200 \mu \mathrm{M} \mathrm{Z2} 2$ is $-34,820 \mathrm{deg} \bullet \mathrm{cm}^{2} \bullet \mathrm{dmol}^{-1}$, four times the value measured for Zwit-1F at an equivalent oligomer concentration $\left(-8,700 \mathrm{deg} \bullet \mathrm{cm}^{2} \bullet \mathrm{dmol}^{-1}\right.$ at $\left.400 \mu \mathrm{M}\right)$. The $\mathrm{MRE}_{205}$ concentration-dependence fits well $(\mathrm{R}=0.999)$ to a monomer-tetramer equilibrium with an association constant of $1.6 \times 10^{16} \mathrm{M}^{-3}$. This value corresponds to a $\mathrm{C}_{50}$ of $4.7 \mu \mathrm{M}\left(\mathrm{C}_{90}=49\right.$ $\mu \mathrm{M}$ ), ten-fold lower than the $\mathrm{C}_{50}$ of Zwit-1F. The CD data are consistent with the AU data in that the concentrations observed in the AU cell range from 9 to $90 \mu \mathrm{M}$, all of which should be at least $65 \%$ folded and tetrameric.

Temperature-dependent CD studies show Z28 to exhibit a concentration-dependent $T_{m}$, an inherent property of protein quaternary structure (Figure $3 \mathrm{~A}$ ). The $\mathrm{Z} 28 \mathrm{~T}_{\mathrm{m}}$, which increases from $73^{\circ} \mathrm{C}$ at $3.125 \mu \mathrm{M}$ to roughly $92^{\circ} \mathrm{C}$ at $31.25 \mu \mathrm{M}$, is higher than the $\mathrm{T}_{\mathrm{m}}$ of $100 \mu \mathrm{M}$ Zwit- $1 \mathrm{~F}$ $\left(69^{\circ} \mathrm{C}\right)$. Roughly $25 \%$ of the $\mathrm{CD}$ signal is lost prior to cooperative unfolding of Z28, indicating flexibility in the folded structure. However, the width of the temperature derivative of the Z28 $\mathrm{CD}$ signal $\left(\delta \mathrm{MRE}_{205} / \delta \mathrm{T}\right)$ at half-maximum is $25^{\circ} \mathrm{C}$ versus $40{ }^{\circ} \mathrm{C}$ for $150 \mu \mathrm{M} \mathrm{Zwit}-1 \mathrm{~F}$, implying increased cooperativity in $\mathrm{Z} 28$ unfolding (Figure 3B). ${ }^{14} \mathrm{Z} 28$ unfolding is $92 \%$ reversible, as judged by recovery of the $\mathrm{CD}$ signal at $25^{\circ} \mathrm{C}$ following thermal denaturation. 15,16

The temperature-independent van't Hoff enthalpy $\left(\Delta \mathrm{H}_{\mathrm{vH}}\right)$ of a self-associating system can be determined from the slope of a plot of $1 / \mathrm{T}_{\mathrm{m}} v s$. $\ln \left[\mathrm{Z}_{\mathrm{T}}\right]$, where $\mathrm{Z}_{\mathrm{T}}$ is the total concentration of monomer units (Figure 3A). ${ }^{14}$ For Zwit-1F and Z28, this analysis yields $\Delta \mathrm{H}_{\mathrm{vH}}$ values of 99 and $124 \mathrm{kcal} \bullet \mathrm{mol}^{-1}$, respectively (see Supporting Information). Thus, both concentration- and temperature-dependent $\mathrm{CD}$ analysis, as well as AU analysis, indicate that Z28 is substantially more stable than Zwit-1F. We note, however, that $\Delta \mathrm{H}_{\mathrm{vH}}$ measurements must be treated with caution, as more thorough calorimetric analysis found the Zwit-1F enthalpy of denaturation to be temperature-dependent. 7,17

We also characterized the Z28 fold by the extent to which it influenced ANS fluorescence and by ${ }^{1} \mathrm{H}$ NMR. ANS increases in fluorescence when sequestered in a hydrophobic environment. 18,19 A protein-dependent increase in ANS fluorescence suggests that the protein core is sufficiently fluid to allow invasion by ANS. In the presence of $200 \mu \mathrm{M} \mathrm{Z28} \mathrm{(96 \%} \mathrm{tetrameric),}$ ANS fluorescence increased 12-fold over background in phosphate buffer at $\mathrm{pH} 7.2$ (see Supporting Information). While direct comparison to Zwit-1F ANS-binding is precluded by the fact that Zwit-1F forms insoluble aggregates in the presence of ANS, a 12-fold fluorescence increase is generally regarded as evidence of a molten hydrophobic core. ${ }^{20}$ Additional evidence for the plasticity of the Z28 core was found in the ${ }^{1} \mathrm{H}$ NMR spectrum (Figure S4 in Supporting Information). At $400 \mu \mathrm{M}$ in phosphate buffer, no discrete amide $\mathrm{N}-\mathrm{H}$ resonances were observed, whereas 10 discrete peaks could be observed in the Zwit-1F amide region at $750 \mu \mathrm{M}$ (95\% folded). The higher affinity, more cooperative fold of Z28 appears to be related its topology, as the hydrophobic core is not as well packed as the Zwit-1F core.

In the absence of high resolution structural characterization, sedimentation velocity AU and size-exclusion chromatography coupled light scattering (SEC-LS) experiments were used to show that the Z28 oligomer adopts a compact, nearly spherical fold $\left(f f f_{0}=1.1\right)$. The hydrodynamic radius $\left(R_{H}=19 \AA\right)$ measured by SEC-LS is consistent with the radius ( $20 \AA$ ) of our computational model of the tetramer and not with an elongated fold (see Supporting Information for models, AU data, and SEC-LS data.)

Inherent in the design of Z28 is the assumption that the flipped helix - which is formally a "retro" $\beta^{3}$-peptide - will present its side chains in a manner that closely resembles the original 
$\beta$-peptide helix in Zwit-1F. This assumption is frequently invalid for $\alpha$-peptide helices: analogous "retro" analogs of the GCN4 leucine zipper domain formed poorly folded mixtures or oligomers of different stoichiometries than their parent. ${ }^{21-23} \mathrm{We}$ propose that the design of Z28 succeeded because of two defining characteristics of the 14-helix: the linear arrangement of side chains along one helix face, a direct consequence of a 3.1 residue repeat, and the nearly flat trajectory of $\beta$-peptide side chains as they emerge from the helix axis. The side chains of Zwit- $1 \mathrm{~F}$ helix 1 on average project at $84.6^{\circ}$ to the helical axis, a value significantly closer to $90^{\circ}$ than the corresponding angle for a GCN4 $\alpha$-helix $\left(77.7^{\circ}\right.$ ) (Figure 4 and Supporting Information). The small deviation of the 14-helix projection angle from $90^{\circ}$ implies that helix flipping will minimally alter side chain display.

In summary, we successfully converted the parallel $\beta$-peptide dimer unit embodied in the octameric Zwit-1F $\beta$-peptide bundle into a linear, single chain 28 residue $\beta$-peptide. We optimized microwave-assisted synthesis conditions to enable a linear assembly of Z28 in sufficient yields and purity to make future analog syntheses routine. Z28 is, to our knowledge, the longest $\beta$-peptide yet synthesized. CD and AU experiments indicate that Z28 is tetrameric as expected. Furthermore, the $\mathrm{CD}$ data show that $\mathrm{Z} 28$ unfolds more cooperatively than Zwit- $1 \mathrm{~F}$, with a higher affinity and a larger $\Delta \mathrm{H}_{\mathrm{vH}}$. Thus, we have overcome the problems associated with Zwit-1F: Z28 is a stable $\beta$-peptide bundle of reasonable stoichiometry with a region of $\beta \mathrm{G}$ residues that should be amenable to functionalization. Z28 is an important step toward protein-like $\beta$-peptides, and the apparent ease of flipping the 14-helical epitope may soon enable the design of even more complex geometries.

\section{ACKNOWLEDGMENT}

This work was supported by grants to A.S. from the NIH and the National Foundation for Cancer Research. E.J.P. thanks the NIH for fellowship support and Dr. Folta-Stogniew of the Keck Foundation Biotechnology Resource Laboratory at Yale University for assistance with SEC-LS.

\section{References}

1. Anfinsen CB. Science 1973;181:223-230. [PubMed: 4124164]

2. Bryson JW, Betz SF, Lu HS, Suich DJ, Zhou HXX, Oneil KT, Degrado WF. Science 1995;270:935941. [PubMed: 7481798]

3. Goodman CM, Choi S, Shandler S, DeGrado WF. Nat. Chem. Biol 2007;3:252-262. [PubMed: 17438550]

4. Benner SA, Sismour AM. Nat. Rev. Genet 2005;6:533-543. [PubMed: 15995697]

5. Qiu XJ, Petersson EJ, Matthews EE, Schepartz A. J. Am. Chem. Soc 2006;128:11338-11339. [PubMed: 16939241]

6. Daniels DS, Petersson EJ, Qiu XJ, Schepartz A. J. Am. Chem. Soc 2007;129:1532-1533. [PubMed: 17283998]

7. Petersson EJ, Craig CJ, Daniels DS, Qiu XJ, Schepartz A. J. Am. Chem. Soc 2007;129:5344-5345. [PubMed: 17425318]

8. Spartan '04. Wavefunction, Inc.; Irvine, CA, USA:

9. Abele S, Guichard G, Seebach D. Helv. Chim. Acta 1998;81:2141-2156.

10. Seebach D, Abele S, Sifferlen T, Hanggi M, Gruner S, Seiler P. Helv. Chim. Acta 1998;81:22182243.

11. Murray JK, Gellman SH. Org. Lett 2005;7:1517-1520. [PubMed: 15816741]

12. Albericio F, Cases M, Alsina J, Triolo SA, Carpino LA, Kates SA. Tetrahedron Lett 1997;38:48534856.

13. Laue TM. Sedimentation equilibrium as thermodynamic tool. Methods in Enzymology: Energetics of Biological Macromolecules 1995;259:427-452.

14. Marky LA, Breslauer KJ. Biopolymers 1987;26:1601-1620. [PubMed: 3663875] 
15. Sturtevant JM. Annu. Rev. Phys. Chem 1987;38:463-488.

16. Although an ideal two-state transition exhibits $100 \%$ reversibility, the thermal denaturation of many natural proteins has been interpreted in terms of a two-state model despite reversibilities as low as $80 \%$. See, for example: Hible G, Renault L, Schaeffer F, Christova P, Radulescu AZ, Evrin C, Gilles AM, Cherfils J. J. Mol. Biol 2005;352:1044-1059. [PubMed: 16140325]

17. Kaya H, Chan HS. Proteins: Struct., Funct., Bioinf 2000;40:637-661.

18. Goto Y, Fink AL. Biochem 1989;28:945-952. [PubMed: 2496758]

19. Semisotnov GV, Rodionova NA, Razgulyaev OI, Uversky VN, Gripas AF, Gilmanshin RI. Biopolymers 1991;31:119-128. [PubMed: 2025683]

20. Lumb KJ, Kim PS. Biochem 1995;34:8642-8648. [PubMed: 7612604]

21. Mittl PRE, Deillon C, Sargent D, Liu NK, Klauser S, Thomas RM, Gutte B, Grutter MG. Proc. Natl. Acad. Sci. USA 2000;97:2562-2566. [PubMed: 10716989]

22. Liu NK, Deillon C, Klauser S, Gutte B, Thomas RM. Protein Sci 1998;7:1214-1220. [PubMed: 9605327]

23. Holtzer ME, Braswell E, Angeletti RH, Mints L, Zhu D, Holtzer A. Biophys. J 2000;78:2037-2048. [PubMed: 10733982] 
A
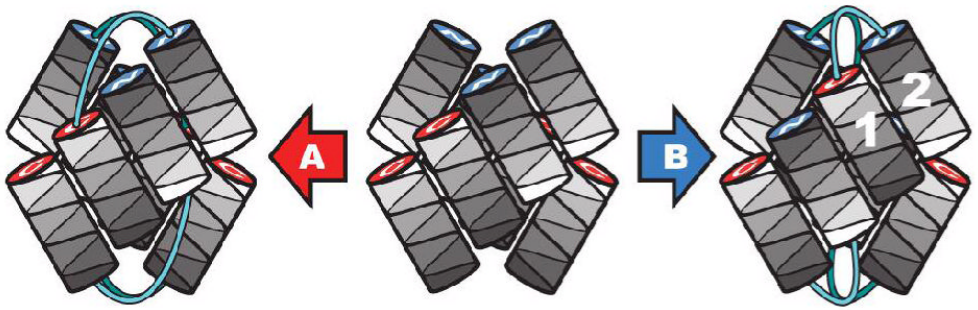

Not Pursued

Zwit-1F Octamer

Z28 Tetramer

B

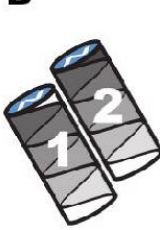

parallel

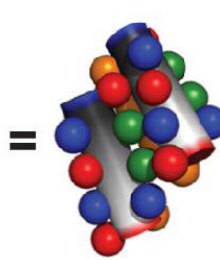

helices

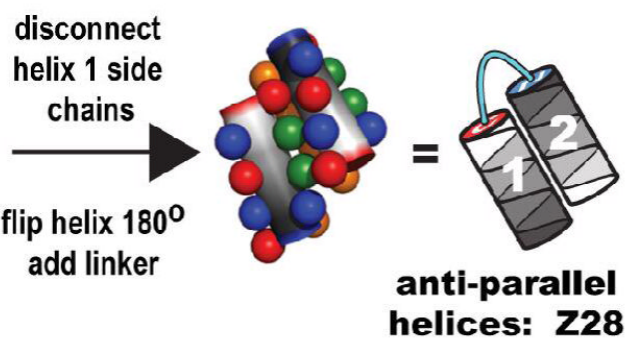

\section{Z28 Sequence}

$\begin{aligned} \text { C } & \beta^{3} D_{1}-\beta^{3} L-\beta^{3} O_{3}-\beta^{3} O_{4}-\beta^{3} L-\beta^{3} F_{6}-\beta^{3} D_{7}-\beta^{3} L-\beta^{3} F_{9}-\beta^{3} O_{10}-\beta^{3} L_{11} \beta^{3} E_{12} \beta G-{ }_{13} \beta G_{14} \\ & \beta^{3} D_{28}-\beta^{3} L_{27}-\beta^{3} O_{26}-\beta^{3} O_{25}-\beta^{3} L-\beta^{3} F_{23} \beta^{3} D_{22}-\beta^{3} L-\beta_{21}^{3} F_{20}^{*} \beta^{3} O_{19}-\beta^{3} L-\beta^{3} E_{17} \beta G G_{16} G_{15}\end{aligned}$

Figure 1.

(A) Two strategies for conversion of the Zwit-1F octamer into a tetramer. (B) Details of strategy B. We began with a parallel dimer unit (helices 1 and 2) from the Zwit-1F crystal structure and proceeded as described in the text. Sphere representations of side chains are coloured by residue type as in the sequence. c) Sequence of Z28. $\beta$-Amino acids are represented by the single letter code of the equivalent $\alpha$-amino acid. $\mathrm{F}^{*}$ denotes $p$-iodophenylalanine and $\mathrm{O}$ denotes ornithine. $\beta \mathrm{G}$ is commonly referred to as $\beta$-alanine. 

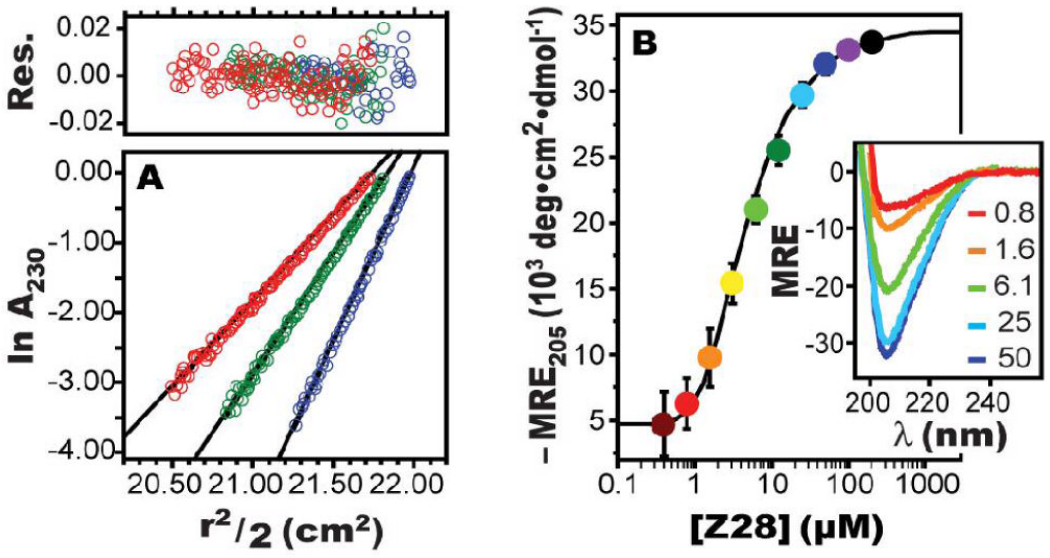

Figure 2.

(A) AU sedimentation equilibrium at 42 kRPM (red), 50 kRPM (green), and 60 kRPM (blue) fit to a single ideal species of $14.8 \mathrm{kDa}(\mathrm{n}=4.0)$. Residuals are displayed with a linear $\mathrm{Y}$-axis scale. (B) Z28 concentration-dependent CD data. The molar residue ellipticity at $205 \mathrm{~nm}$ $\left(\mathrm{MRE}_{205}\right)$ fit to a monomer-tetramer equilibrium where $\mathrm{MRE}_{\mathrm{mon}}=4.7 \times 10^{3}$

$\operatorname{deg} \bullet \mathrm{cm}^{2} \bullet \mathrm{dmol}^{-1}, \mathrm{MRE}_{\mathrm{tet}}=34.8 \times 10^{3} \mathrm{deg} \bullet \mathrm{cm}^{2} \bullet \mathrm{dmol}^{-1}$, and $\operatorname{lnK}_{\mathrm{a}}=37.5$. Inset: Wavelengthdependent $\mathrm{CD}$ data at the indicated concentrations (in $\mu \mathrm{M}$ ). MRE in units of $10^{3}$

$\operatorname{deg} \bullet \mathrm{cm}^{2} \cdot \mathrm{dmol}^{-1}$. AU and CD measurements were performed in $10 \mathrm{mM}$ phosphate, $200 \mathrm{mM}$ $\mathrm{NaCl}(\mathrm{pH} 7.2)$. 

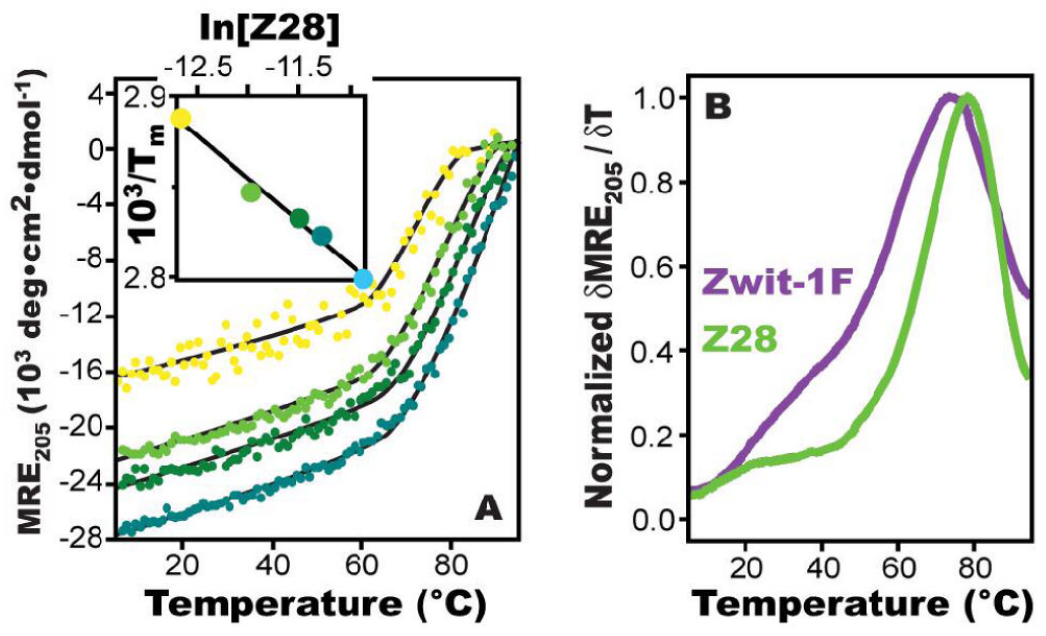

Figure 3.

(A) Temperature-dependence of the molar residue ellipticity at $205 \mathrm{~nm}\left(\mathrm{MRE}_{205}\right)$ of 3.125 (yellow), 6.25 (light green), 10.0 (dark green), and 12.5 (teal) $\mu \mathrm{M} \mathrm{Z28}$ in phosphate buffer (pH 7.2). Inset: Inverse thermal denaturation midpoints $\left(1 / \mathrm{T}_{\mathrm{m}} \mathrm{s}\right.$, in $\left.10^{-3} \mathrm{~K}^{-1}\right)$ at various concentrations of Z28 $(3.125,6.25,10.0,12.5$, and $18.75 \mu \mathrm{M})$ fit to Equation 1 as described in Supporting Information. (B) Normalized temperature derivatives of $\mathrm{MRE}_{205}$ for $150 \mu \mathrm{M}$ Zwit-1F and $6.25 \mu \mathrm{M}$ Z28. 

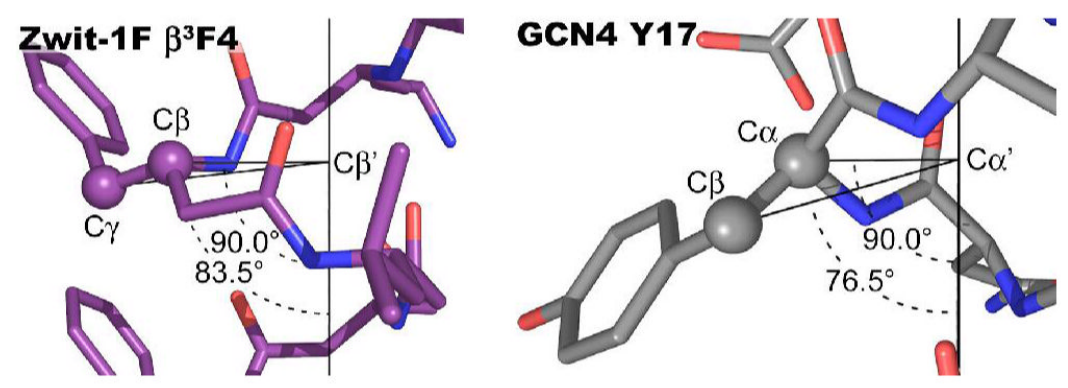

Figure 4.

Left: The Zwit-1F sidechain display angle, made by the $\gamma$ carbon $(\mathrm{C} \gamma)$, the projection of the $\beta$ carbon on the helix axis $\left(C \beta^{\prime}\right)$, and the $C$-terminus of the helical axis $\left(C^{\prime}\right)$. The $C \gamma, C \beta^{\prime}, C^{\prime}$ angle is shown for reference. Right: The analogous $\mathrm{C} \beta, \mathrm{C} \alpha^{\prime}, \mathrm{N}^{\prime}$ sidechain display angle and $\mathrm{C} \alpha, \mathrm{C} \alpha^{\prime}, \mathrm{N}^{\prime}$ reference angle for GCN4 ( $\mathrm{N}^{\prime}=$ helical axis $\mathrm{N}$-terminus). 


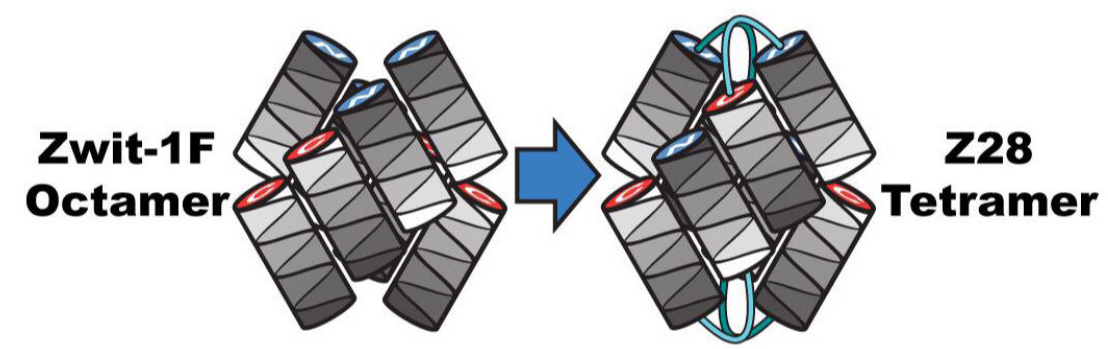

A twenty-eight residue "retro" $\beta$-peptide has been designed to self-assemble as a tetramer, successfully recapitulating the octameric $\beta$-peptide bundle complex Zwit-1F. Z28, the largest $\beta$-peptide synthesized to date, was achieved in a linear, microwave-assisted synthesis in $19 \%$ isolated yield and high purity. Z28 forms the expected tetrameric complex and is more stable and cooperative in its folding than Zwit-1F. The successful design and synthesis of Z28 is an important step toward true $\beta$-amino acid proteins. 